\title{
Modeling Fireside Corrosion Rate in a Coal Fired Boiler Using Adaptive Neural Network Formalism
}

\author{
Amrita Kumari, ${ }^{a, *}$ S. K. Das $^{b}$ and P. K. Srivastava ${ }^{a}$ \\ ${ }^{a}$ Birla Institute of Technology, Mesra, Ranchi 835 215, India \\ ${ }^{b}$ CSIR -National Metallurgical Laboratory, Jamshedpur 831 007, India
}

Received 24 August 2015; accepted 13 November 2015

\begin{abstract}
In this paper, an efficient artificial neural network (ANN) model using multi-layer perceptron (MLP) philosophy has been proposed to predict the fireside corrosion rate of super heater tubes in coal fire boiler assembly, using operational data of an Indian typical thermal power plant. The input parameters comprise coal chemistry, namely, coal ash and sulfur contents, flue gas temperature, $\mathrm{SO}_{\mathrm{X}}$ concentrations in flue gas, fly ash chemistry $\left(w t \% \mathrm{Na}_{2} \mathrm{O}\right.$ and $\mathrm{K}_{2} \mathrm{O}$ ). An efficient gradient based network training algorithm has been employed to minimize the network training errors. Effects of coal ash and sulfur contents, wt $\%$ of $\mathrm{Na}_{2} \mathrm{O}$ and $\mathrm{K}_{2} \mathrm{O}$ in fly ash and operating variables such as flue gas temperature and percentage excess air intake for coal combustion on the fireside corrosion behavior of super heater boiler tubes have been computationally investigated and parametric sensitivity analysis has been undertaken. It has been observed that ash and sulfur contents of coal, flue gas temperature and fly ash chemistry have a relatively predominant influence on the rate of fireside corrosion with respect to other parameters. Quite good agreement between ANN model predictions and the measured values of fireside corrosion rate has been observed, which is corroborated by the regression fit between these values.
\end{abstract}

Keywords: Fireside corrosion, superheater tubes, artificial neural network model, coal composition, boiler fly ash and flue gas.

\section{Introduction}

Fireside corrosion issues have always been a concern for the power generation industry, but for the last few decades, when only fossils fuels, particularly coal, were used as fuels, it has been aggravated. At the present, due to the introduction of new technologies to improve the efficiency and facilitate $\mathrm{CO}_{2}$ and $\mathrm{CO}$

\footnotetext{
* Corresponding author. E-mail address: amrita.pandey08@gmail.com
} 
reductions in power plants, fireside corrosion of heat exchangers has become a major operational and techno - economic issue to the power plant industry and manufacturers. Contaminants, such as alkali, chlorine, and sulfur vaporize during gasification and combustion of coal, eventually condense on metal surfaces and remove the protective layer from those surfaces by chemical reaction, fluxing, or fracture [1]. While the boiler operating conditions are important variables, the coal chemistry also plays a vital role in fireside corrosion. Impurity constituents of coal (alkali metals and chlorine etc.) are well known to accelerate corrosion wastage [2]. High sulfur and chlorine contents in the coal have long been recognized as a major cause for boiler tube corrosion on both the waterfall and superheater / reheater surfaces. Fig. 1 shows a typical schematic of an Indian operating power plant. The effects of other constituents on corrosion, such as the alkali and alkaline metal concentrations, as well as the total ash content, are also important but less understood. Corrosion mainly depends on fuel inorganic chemistry and operating conditions. The chemical reaction mechanisms of the inorganic content depend on boiler operating conditions. This may lead to different pathways for compounds that initiate or accelerate the corrosion process. In pulverized-coal-fired boilers, hightemperature corrosion due to chlorine and sulphur is potentially troublesome. The forms in which chlorine occurs are important, as they determine the mineral transformation during combustion, which ultimately affects the fireside corrosion behavior of the species, and their potential for removal during the fuel preparation, as a remedial measure for fireside problems [3]. It may be noted that in Indian coal, the chlorine content is much lesser and consequently its influence on fireside corrosion rate is neither alarming nor an operational issue. While higher efficiencies and lower emissions can be realized from an existing coal combustion system, accelerated fireside corrosion is also expected to occur on the boiler tubes. For instance, low- $\mathrm{NO}_{\mathrm{X}}$ combustion produces $\mathrm{H}_{2} \mathrm{~S}$ in the flue gas and FeS in the deposit, due to incomplete combustion of the sulphur-bearing species in coal. Both of these sulfides are known to increase fireside corrosion on the waterfalls via sulfidation, although the corrosion mechanisms are distinctly different [4].

The fireside corrosion of various components of a coal-fired boiler may be attributed to the following:

- Reducing (sub-stoichiometric) conditions caused by impingement of incompletely combusted coal particles and flames,

- Accelerated oxidation from overheating,

- Molten salt or slag-related attack.

The fireside corrosion is generally localized in regions specifically near the walls of the burners. Reducing atmospheric corrosion can result from direct reaction of the waterwall tubes with a sub-stoichiometric gaseous environment containing sulphur, or with partially combusted char containing FeS. The reducing conditions have two major influences on the corrosion process. First, they tend to lower the melting point of any deposited slag, increasing its ability to dissolve the normal oxide scales, and second, the stable gaseous sulphur compounds include $\mathrm{H}_{2} \mathrm{~S}$, which is more corrosive than $\mathrm{SO}_{2}$ that prevails under oxidizing 
conditions $[5,6]$. The overheating leads to an accelerated oxidation of both the fireside and the steam side surfaces of the tubes that produces thickened, hard scales. Above $570{ }^{\circ} \mathrm{C}$, a considerable non - protective scale of wustite $(\mathrm{FeO})$ can be formed on iron, which culminates in rapid oxidation [7].

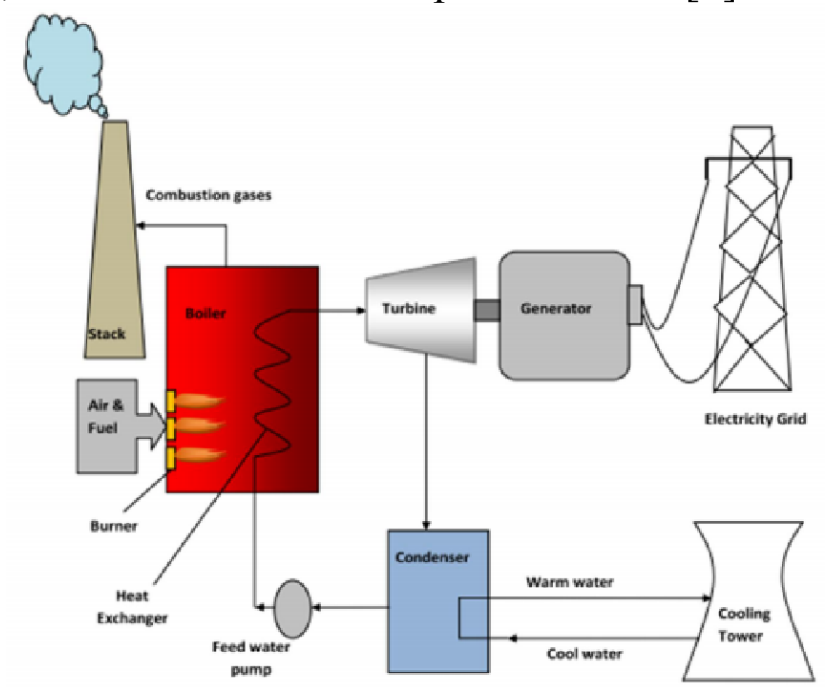

Figure 1. Schematics of a coal fired boiler assembly.

\section{Mechanisms and causes and of Fireside corrosion}

Fireside corrosion is often a very complicated process. Generally, the same corrosion types as those from the steam side can be found in the fireside of a tube, but the acid and base corrosion mechanisms are usually defined differently. Corrosion of super-heaters has become the limiting factor in the attempt of increasing the final steam temperature in energy production. The strength of present steels would allow very high steam pressures and temperatures, but the high oxidation rate or superheater corrosion caused by contaminants in fuel limits the maximum allowed temperature, especially in the combustion of biomass and recycled fuels [3,4]. Superheater corrosion can take place inside the tube, as steam side corrosion, or outside the tube, as fireside corrosion. The steam side corrosion is mainly due to faults in the steam quality control, while the fireside corrosion is caused by corrosive components present in the flue gas. The methods of measuring these two main corrosion types differ remarkably. It is seldom possible to measure directly the thickening of the oxide scale inside a tube, while a significant material loss on the outside can be detected with smaller effort. Further, coal exhibits wide variations in many of its properties, including composition. Low-rank coals commonly contain relatively large amounts of organically associated elements such as $\mathrm{Na}, \mathrm{Mg}, \mathrm{Ca}, \mathrm{K}$, and $\mathrm{Sr}$, present as salts of organic acid groups, as well as mineral grains, although they commonly contain less chlorine than high-rank coals. The Indian coals in general are low rank coals having much less chlorine contents [8]. By contrast, high-rank coals commonly contain more iron and sulfur than low-rank coals. When coal particles are fired into the boiler furnace, the moisture and the volatile species are driven off; the fixed carbon in the pulverized particles begins to burn. The contained mineral matter may be melted or vaporized, and is largely oxidized. The sulphur- 
bearing compounds in the coal (such as FeS) are converted to oxides, such as $\mathrm{Fe}_{2} \mathrm{O}_{3}, \mathrm{~K}_{2} \mathrm{O}, \mathrm{Na}_{2} \mathrm{O}, \mathrm{SO}_{2}$ and $\mathrm{SO}_{3}$. The relative proportions of $\mathrm{SO}_{2}$ and $\mathrm{SO}_{3}$ in the flame depend on the oxygen availability and the flame temperature. $\mathrm{SO}_{2}$ is thermodynamically favored at higher temperatures; the formation of $\mathrm{SO}_{3}$ can be catalyzed by certain metal oxides. Thus, the gaseous species released, as the coal passes through the flame, contain potential corrodents such as sulphur, vapor of alkali metal salts, and chlorine compounds [9]. For high-temperature corrosion due to sulfur, the presence of alkali pyrosulfates in furnace wall deposits and alkali-iron trisulfates on the leading edge of the final superheater tube surface is the primary cause for tube wastage. The sulfates interact with $\mathrm{Fe}_{2} \mathrm{O}_{3}$ in ash and with $\mathrm{SO}_{3}$ present at the tube surface, to form alkali tri-sulfates. The fireside corrosion rate enhances due to formation and de-stabilization of molten complex alkali-iron tri-sulphates, with increasing temperature. Some of the most common reactions of forming alkali-iron tri- sulphates are [10]:

$$
\begin{aligned}
& \mathrm{SO}_{2}+1 / 2 \mathrm{O}_{2} \leftrightarrow \mathrm{SO}_{3} \\
& \mathrm{Fe}_{2} \mathrm{O}_{3}+3 \mathrm{SO}_{3} \leftrightarrow \mathrm{Fe}_{2}\left(\mathrm{SO}_{4}\right)_{3} \\
& 3(\mathrm{Na} / \mathrm{K})_{2} \mathrm{SO}_{4}+\mathrm{Fe}_{2}\left(\mathrm{SO}_{4}\right)_{3} \leftrightarrow 2(\mathrm{Na} / \mathrm{K})_{3} \mathrm{Fe}\left(\mathrm{SO}_{4}\right)_{3}
\end{aligned}
$$

Compounds that have been recognized as having the potential to form in deposits and cause fireside corrosion of tube surfaces include the following: sulphate deposits; pyro-sulphates, e.g. $(\mathrm{Na}, \mathrm{K})_{2} \mathrm{~S}_{2} \mathrm{O}_{7}$; alkali-iron tri-sulphates, e.g. ( $\mathrm{Na}$, $\mathrm{K})_{3} \mathrm{FeS}_{2}\left(\mathrm{SO}_{4}\right)_{3}$; mixed sulphates, e.g. $(\mathrm{Na}, \mathrm{K}, \mathrm{Fe})_{x} \mathrm{SO}_{4}$; chloride deposits, with mixed compositions, including $\mathrm{Na}, \mathrm{K}, \mathrm{Fe}, \mathrm{Ca}, \mathrm{Mg}$, and other metal elements depending on the fuel used; and carbonates, with mixed compositions including $\mathrm{Na}, \mathrm{K}, \mathrm{Fe}, \mathrm{Ca}, \mathrm{Mg}$, and other metal elements depending on the fuel used [11]. The quality of coal used is very important. It has been proposed [2] that there are, in general, three categories rankings for the corrosiveness of coals, based on the sum of the percentages of water-soluble sodium and potassium in the coal, as shown in Table 1.

Table 1. Coal corrosiveness classification index.

\begin{tabular}{|c|c|}
\hline Water-soluble $\mathbf{N a}+\mathbf{K}$ (Wt. \%) & Corrosiveness \\
\hline$<0.5$ & Low \\
\hline $0.5-1.0$ & Medium \\
\hline$>1.0$ & High \\
\hline
\end{tabular}

Chlorine (more than $0.2 \mathrm{wt} \%$ ) has been found to promote the release of both $\mathrm{Na}$ and $\mathrm{K}$ into the flame [12], and acts as a strong catalyst for the molten tri-sulphate attack. There is also evidence that HCI formed in the flame can destroy the $\mathrm{Fe}_{2} \mathrm{O}_{3}$ layer on a steel surface, thereby exposing it to additional oxidative attack $[3,4]$. Research on alkali tri-sulfates reveals that high-temperature corrosion of furnace walls and superheater surfaces is minimized by maintaining an oxidizing environment and avoiding flame impingement on furnace walls. 


\section{Artificial Intelligence applications in corrosion modeling}

Quantitative determination of fireside corrosion rates, in conjunction with pertinent mechanisms as a function of boiler coal chemistry, fly ash chemistry and operating parameters based on first principle kinetic modeling, has remained a fairly difficult topic. This is due to the phenomenological complexity and sometimes non-linear relationship between the dependent and independent variables of the fireside corrosion phenomenon. Therefore, first principle based kinetic model predictions are not always amenable to realistic plant operating conditions. Therefore, simplified assumptions are often made to overcome a phenomenological complexity, which idealizes realistic problems. Recently, Data driven Artificial Intelligence (AI) or Computational Intelligence (CI) based techniques are increasingly used with to functionally map, in an accurate way, the input-output relationship of complex corrosion processes, although these are quite scanty. In principle, AI techniques (such as ANN, Fuzzy logic and Genetic algorithms are intelligent information-treatment systems with the characteristics of adaptive learning.

Application of an artificial neural network (ANN) model has been reported for data driven modelling for prediction of ash deposition in boiler heat transport system [13]. ANN has also been developed successfully to characterize thermal behavior of boiler tubes in the presence of fouling on the basis of plant data [14], and it has also been reported that such models have been applied to control and minimize the effect of fouling in biomass boilers [15]. Application of an expert system based theoretical approach for boiler fouling assessment has been proposed [16]. A comparative study of Fuzzy logic and ANN has been reported [17] for the prediction of the remaining life of boiler tubes subjected to various damage mechanisms. An adaptive Neuro-Fuzzy technique has been attempted [18] for predicting and characterizing coal slagging in a power plant. However, application of ANN modeling to predict the oxidation scale deposition rate in boiler operations is relatively scanty in the published literature.

The objective of the present work is to develop a multi-layer feed forward ANN model to predict explicitly the fireside corrosion rate, as a function of measured plant data (input/output parameters), namely coal ash and sulfur contents, wt $\%$ of $\mathrm{Na}_{2} \mathrm{O}$ and $\mathrm{K}_{2} \mathrm{O}$ in fly ash, and operating variables such as flue gas temperature and percentage excess air intake for coal combustion of a typical coal fired Indian operating boiler. The proposed ANN model also attempts to characterize effects of some of the operational parameters on the fireside corrosion behavior. In this proposed ANN model, efficient gradient based network training algorithm and optimized neural network architecture have been incorporated to improve the network learning algorithm and to minimize training errors during the network learning process.

\section{Adaptive neural networks modeling of fireside corrosion rate}

MLP is the most popular neural network architecture in use today [19, 20]. MLP is a network of simple neurons called perceptrons. The perceptron computes a single output from multiple real-valued inputs by forming a linear combination according to its input weights, and then possibly putting the output through some 
nonlinear activation. The output from a given neuron is calculated by applying a transfer function to a weighted summation of its input to give an output, which can serve as input to other neurons. The framework of MLP concept is shown in figure 2. Mathematically, this can be given as:

$$
\alpha_{j k}=f_{k}\left(\sum_{i=1}^{N_{k-1}} w_{i j k} \alpha_{i(k-1)}+\beta_{j k}\right)
$$

where $\alpha_{j k}$ is neuron $j$ 's output from $k$ 's layer and $\beta_{\mathrm{jk}}$ is the bias weight for neuron $j$ in layer $k$. The model fitting parameters $w_{\mathrm{ijk}}$ are the connection weights and $f_{k}$ 's are activation functions. Most neural networks will tend to forget old information if we attempt to add new information incrementally. When developing an artificial neural network to perform a particular pattern-classification operation, one typically proceeds by gathering a set of exemplars, or training patterns, then using these exemplars to train the system. During the training, information is encoded in the system by the adjustment of weight values. Once the training is deemed to be adequate, the system is ready to be put into production, and no additional weight modification is permitted. This operational scenario is acceptable, provided the problem domain has well-defined boundaries and is stable. Under such conditions, it is usually possible to define an adequate set of training inputs for whatever problem is being solved.

\section{Optimal network learning algorithm}

MLP is usually trained using the error back propagation algorithm. This popular algorithm works by iteratively changing a network's interconnecting weights, such that the overall error (i.e. between observed values and modeled network outputs) is minimized. In principle, network training/ learning uses one of several possible optimization methods to minimize this error term. There are various back propagation (BP) algorithms, such as Scaled Conjugate Gradient (SCG), Levenberg-Marquardt (LM), Gradient Descent with Momentum (GDM), variable learning rate Back propagation (GDA) and Resilient back Propagation (RP) [19]. There is a variety of network optimization techniques that uses gradient of a function to be optimized. One of the most recently developed efficient versions of the quasi-Newton optimization methods is the BFGS algorithm [21, 22], which has largely replaced the classical DFP algorithm.

In general, the quasi-Newton method was derived from quadratic objective function. The inverse of the Hessian matrix, $\mathrm{H}$ (shown in eqn. 8) is used to bias the gradient direction $[23,24]$.

$$
B=H^{-1}
$$

In the quasi-Newton training method, the weights are updated using the following iterative procedure:

$$
W_{i+1}=W_{i}-\eta B_{i} g_{i}
$$


The matrix B here needs not be computed. It is successively estimated employing rank 1 or rank 2 updates, following each line search in a sequence of search directions. This is algorithmically given as follows:

$$
B_{i}=B_{i}-\Delta B_{i}
$$

In this iterative algorithm, $B_{i-1}$ is the previous value of $B$.

The two important algorithmic relationships to compute $\Delta B_{\mathrm{i}}$ are as follows [24]:

$$
\Delta B_{i}=\frac{d d^{T}}{d^{T} \Delta g}-\frac{B_{i-1} \Delta g \Delta g^{T} B_{i-1}}{\Delta g^{T} B_{i-1} \Delta g}
$$

The above expression pertains to DFP algorithm and the equation given below is the BFGS algorithm:

$$
\Delta B_{i}=\left(1+\frac{\Delta g^{T} B_{i}-1 \Delta g}{d^{T} \Delta g}\right) \frac{d d^{T}}{d^{T} \Delta g}-\frac{d \Delta g^{T} B_{i}-1+B_{i}-1 \Delta g d^{T}}{d^{T} \Delta g}
$$

where,

$$
\begin{gathered}
d=w_{i}-w_{i-1} \text { and } \\
\Delta_{g}=g_{i}-g_{i-1} \\
\Delta B=B_{i}-B_{i-1}
\end{gathered}
$$

Thus, BFGS potentially reduces the number of function evaluations [24, 25] required to achieve an optimization procedure which has been successfully applied elsewhere by one of the authors [26].

\section{Network configuration Input-Output variables}

The following activation functions, denoted by $\Phi(\mathrm{v})$, have been used in this neural model. First, there is the Threshold Function which takes on a value of 0 , if the summed input is less than a certain threshold value of $\boldsymbol{v}$, and the value of 1 , if the summed input is greater than or equal to the threshold value $[27,28]$.

$$
\varphi(v)= \begin{cases}1 & \text { if } v \geq 0 \\ 0 & \text { if } v<0\end{cases}
$$

Secondly, there is the Piecewise-Linear function. This function again can take on the values of 0 or 1 , but can also take on values between that, depending on the amplification factor in a certain region of linear operation.

$$
\varphi(v)=\left\{\begin{array}{cc}
1^{-} & v \geq \frac{1}{2} \\
v & -\frac{1}{2}>v>\frac{1}{2} \\
0 & v \leq-\frac{1}{2}
\end{array}\right.
$$


Thirdly, there is the sigmoid function. This function can range between 0 and 1 , but it is also sometimes useful to use the -1 to 1 range. The sigmoid function is the hyperbolic tangent function given below [29]:

$$
\varphi(v)=\tanh \left(\frac{v}{2}\right)=\frac{1-\exp (-v)}{1+\exp (-v)}
$$

Table 2. A typical ANN modeling data segment.

\begin{tabular}{|c|c|c|c|c|c|c|c|}
\hline Corrosion_rate & flue gas & coal_ash & coal_s & $\mathrm{Na}_{2} \mathrm{O} \_$Ash & $\mathrm{K}_{2} \mathrm{O} \_$Ash & SOX_Flue_gas & excess_air \\
\hline (mm/year) & temp ${ }^{\circ} \mathrm{C}$ & $\%$ & $\%$ & wt (\%) & $\mathbf{W t}(\%)$ & $(\mathrm{mg} / \mathrm{m} 3)$ & (\%) \\
\hline 0.47 & 178 & 39.7 & 0.6 & 0.35 & 1.24 & 237.1 & 34.7 \\
\hline 0.49 & 178 & 39.9 & 0.6 & 0.35 & 1.23 & 237.3 & 34.9 \\
\hline 0.49 & 176 & 39.9 & 0.6 & 0.35 & 1.24 & 237.4 & 34.9 \\
\hline 0.46 & 175 & 39.6 & 0.6 & 0.35 & 1.25 & 236.9 & 34.6 \\
\hline 0.43 & 175 & 39.3 & 0.6 & 0.34 & 1.22 & 236.5 & 34.3 \\
\hline 0.45 & 175 & 39.5 & 0.6 & 0.34 & 1.21 & 236.7 & 34.5 \\
\hline 0.43 & 175 & 39.3 & 0.6 & 0.34 & 1.2 & 236.4 & 34.3 \\
\hline 0.43 & 175 & 39.3 & 0.6 & 0.34 & 1.21 & 236.4 & 34.3 \\
\hline 0.4 & 175 & 39 & 0.6 & 0.34 & 1.22 & 236 & 34 \\
\hline 0.35 & 172 & 38.5 & 0.5 & 0.33 & 1.15 & 235.2 & 33.5 \\
\hline 0.37 & 171 & 38.7 & 0.6 & 0.34 & 1.19 & 235.6 & 33.7 \\
\hline 0.23 & 168 & 37.3 & 0.5 & 0.32 & 1.1 & 233.4 & 32.3 \\
\hline 0.24 & 168 & 37.4 & 0.5 & 0.32 & 1.12 & 233.5 & 32.4 \\
\hline 0.3 & 166 & 38 & 0.5 & 0.33 & 1.17 & 234.5 & 33 \\
\hline 0.2 & 166 & 37 & 0.4 & 0.32 & 1.11 & 233 & 32 \\
\hline 0.23 & 165 & 37.3 & 0.5 & 0.32 & 1.09 & 233.4 & 32.3 \\
\hline 0.13 & 165 & 36.3 & 0.4 & 0.31 & 1.06 & 232 & 31.3 \\
\hline 0.18 & 165 & 36.8 & 0.4 & 0.32 & 1.11 & 232.7 & 31.8 \\
\hline 0.13 & 164 & 36.3 & 0.4 & 0.31 & 1.07 & 231.9 & 31.3 \\
\hline 0.12 & 164 & 36.2 & 0.4 & 0.31 & 1.06 & 231.7 & 31.2 \\
\hline 0.04 & 163 & 35.4 & 0.3 & 0.3 & 1.01 & 230.6 & 30.4 \\
\hline 0.04 & 160 & 35.4 & 0.3 & 0.3 & 1 & 230.6 & 30.4 \\
\hline
\end{tabular}

The input, output variables and their data ranges, for a $250 \mathrm{MW}$ typical Indian coal fired boiler system used in the ANN models, are shown in Table 2. Table 3 shows the chemistry of a typical Indian thermal coal used in power plants. Input data set is segmented [26,27] into three subsets, namely, one for training (learning), one for selection (validation), and one for testing (prediction) using roughly 2:1:1 ratio. Out of 1000 dataset from plant measurements, 500 dataset are used as training samples, 250 as validation samples and the remaining 250 samples have been utilized for prediction. The selection basis of these three dataset for training, selection, and testing has been random. The current network topology is designed with nine input neurons and one output neuron, four and thirteen hidden layers (two separate cases) to numerically simulate the fireside corrosion process. Sometimes, the pitfall of MLP based network is that too few neurons in the hidden layer may introduce higher error during network selection in the model, where the relations between different variables are not well developed. On the other hand, too many neurons in the hidden layer may cause 
the model to over-fit the training data, resulting in a less optimal solution for selection data. The neural prediction based on two feed forward network architectures (MLP 9-4-1 and MLP 9-13-1) is compared with the regression fit between predicted and measured fireside corrosion rate data. It may be observed from the simulation results (Fig. 2) that all these two network architectures have an almost similar accuracy level. The network architecture nomenclature is as follows: MLP 9-4-1 specify a multilayer perceptron network and the subsequent digits indicate the number of input neurons(9), the number of hidden neurons(4) and the number of output neurons(1), respectively.

Table 3. Chemical analysis of Indian coal.

\begin{tabular}{|c|c|}
\hline Characteristics & Indian \\
\hline Total moisture ash \% & $10-20$ \\
\hline Ash \% & $25-50$ \\
\hline Volatile matter \% & $16-30$ \\
\hline Fixed carbon \% & $24-40$ \\
\hline Carbon \% & $30-55$ \\
\hline Hydrogen \% & $2-4$ \\
\hline Nitrogen \% & $0.7-1.15$ \\
\hline Sulphur \% & $0.3-0.8$ \\
\hline Oxygen \% & $4-8$ \\
\hline GCV(kcal/kg) & $2800-5000$ \\
\hline Abrasive index & $40-60$ \\
\hline Ash softening temperature & Above $1300{ }^{\circ} \mathrm{C}$ \\
\hline Hard groove index (HGI) & $50-110$ \\
\hline
\end{tabular}

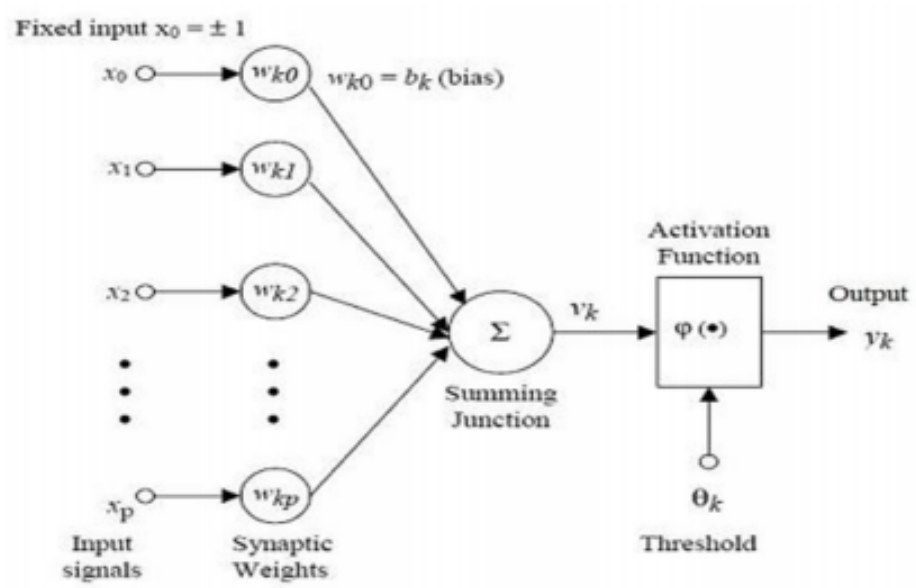

Figure 2. Neural network simulation architecture.

\section{Results and discussion}

Fig. 3 depicts numerical predictions of fireside corrosion rates on boiler superheater tubes (in a typical Indian power plant). The neural prediction based on two network architectures (MLP 9-4-1 and MLP 9-13-1) is compared with the regression fit between predicted and measured data. It may be observed from the simulation that all these two proposed network architectures have almost similar prediction characteristics. 


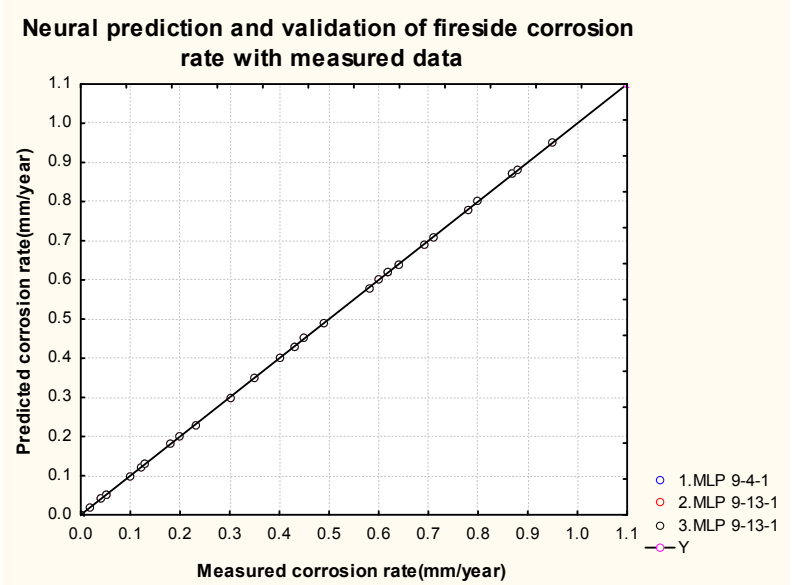

Figure 3. Validation of neural prediction with measured data.

Fig. 4 shows predicted fireside corrosion rate as a function of sulphur content in a typical thermal Indian coal. It may be observed from the figure that the fireside corrosion rate monotonically increases with an increased sulphur content in coal. The corrosion rate varies from 0.1 to $1.0 \mathrm{~mm} /$ year (approx.) with respect to sulphur content of coal ranging from $0.3 \%-1.0 \%$.There is comparatively less sulfur content present in Indian coal as compared to British coal. However, the sulphur content is sufficient to the extent it ensures that any sodium and potassium compounds released in the combustion process form fusible sulfates. Sulfur typically is found as sodium sulfate in coal ash. At high temperature it dissociates [12] and eventually alters the basicity of the molten ash deposits. Sulfur reacts with sodium in the melt altering the concentration of $\mathrm{Na}_{2} \mathrm{O}$, and thereby changing the corrosion rates.

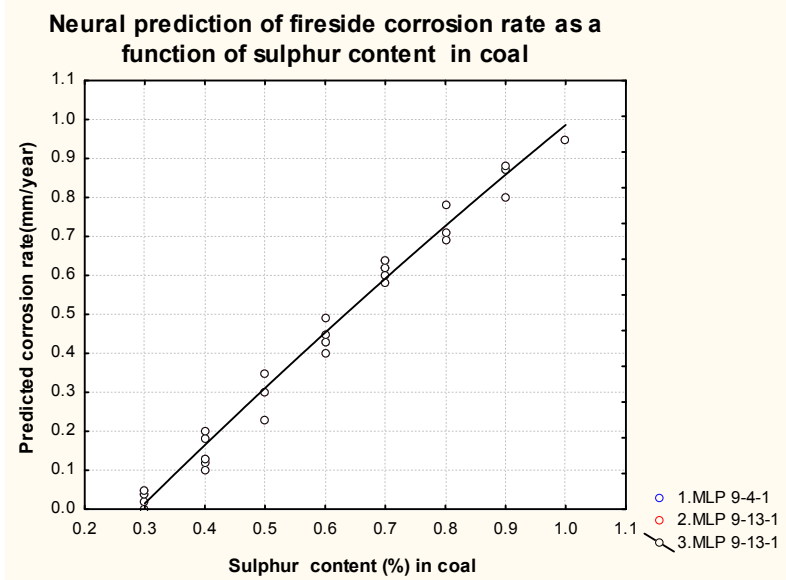

Figure 4. Prediction of fireside corrosion rate with sulphur content in coal.

Fig. 5 shows predicted fireside corrosion rates as a function of $\mathrm{SO}_{\mathrm{X}}$ in flue gas. It may be observed from the figure that the corrosion rate linearly increases with increased $\mathrm{SO}_{\mathrm{X}}$ percentage in flue gas. The predictions conform-to the realistic situation [30]. The corrosion rate varies from $0.1-0.95 \mathrm{~mm} /$ year (approx.) with respect to $\mathrm{SO}_{\mathrm{X}}$ concentrations of $230-245 \mathrm{mg} / \mathrm{m} 3$ in flue gas. Fireside corrosion 
in boiler areas is associated with the deposition of alkali sulfates onto the metal surface, their concentration being increased at the metal surface by absorption onto the porous fly ash. The salts formed are usually molten and contain free sulfur trioxide in flue gas, which dissolves the protective oxide film to form iron and chromium based sulfates.

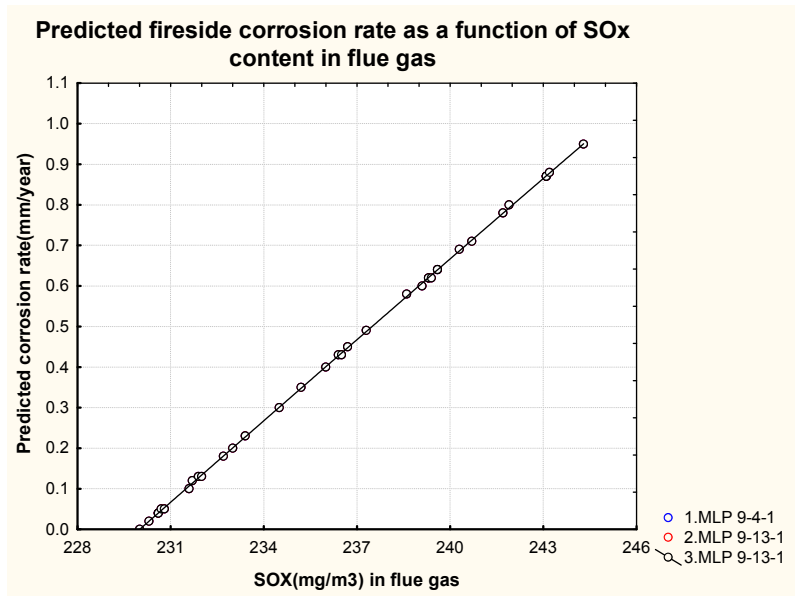

Figure 5. Prediction of fireside corrosion rate with SOx content in flue gas.

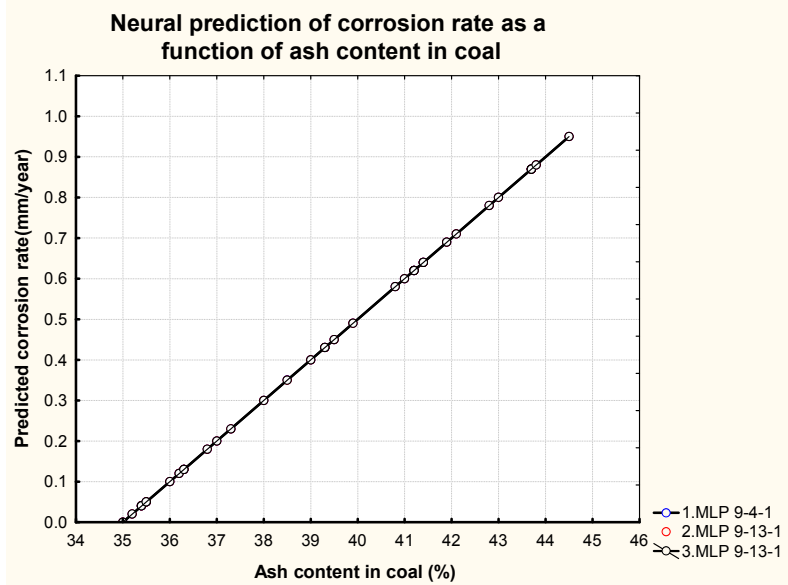

Figure 6. Prediction of fireside corrosion rate with ash content in coal.

Fig. 6 shows predicted fireside corrosion rates as a function of ash content in a typical Indian coal. It may be observed from the figure that the fireside corrosion rate enhances with an increased value of ash content in the coal. The fireside corrosion rates varies from 0.05 to $0.97 \mathrm{~mm} /$ year (approx.) with respect to an ash content range $35 \%-45 \%$ in the coal. With an increase in the ash content in coal the mineral matter content in coal also increases accordingly. The mineral matter main constituents are alkali metal oxides (sodium and potassium compounds primarily). These alkali metal forms oxides at high temperatures and has low melting point ranges from 540 to $750{ }^{\circ} \mathrm{C}$. These oxides fuse with the sulphur compounds and form highly corrosive alkali metal sulphates deposits on to the heat transport surfaces, accelerating corrosion. Fig. 7 depicts variation of predicted corrosion rates as a function of flue gas temperature. It may be observed from the figure that the corrosion rate enhances with an increase in flue 
gas temperature. Corrosion reactions get activated with higher activation energy as the flue gas temperature increases [10, 31].

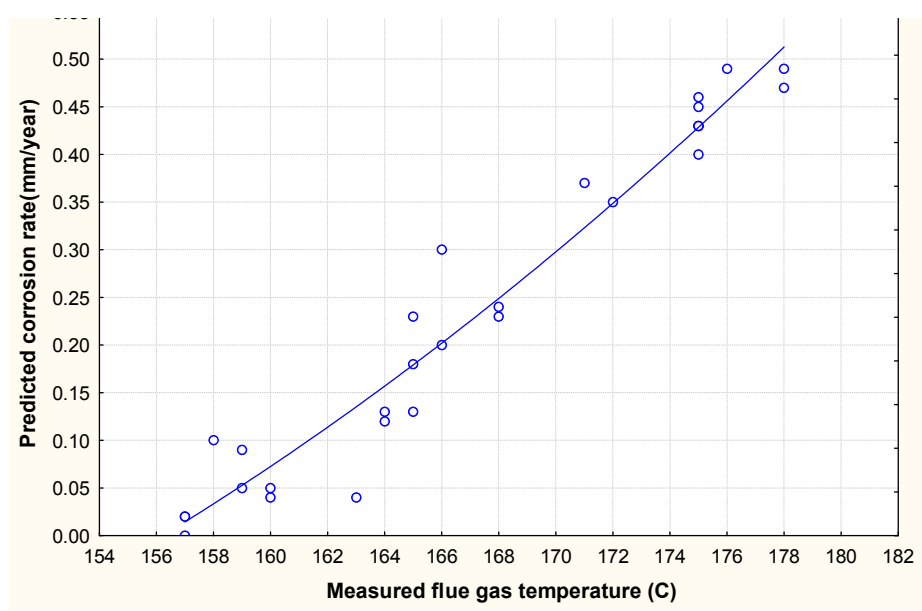

Figure 7. Prediction of fireside corrosion rate with exhaust flue gas temperature.

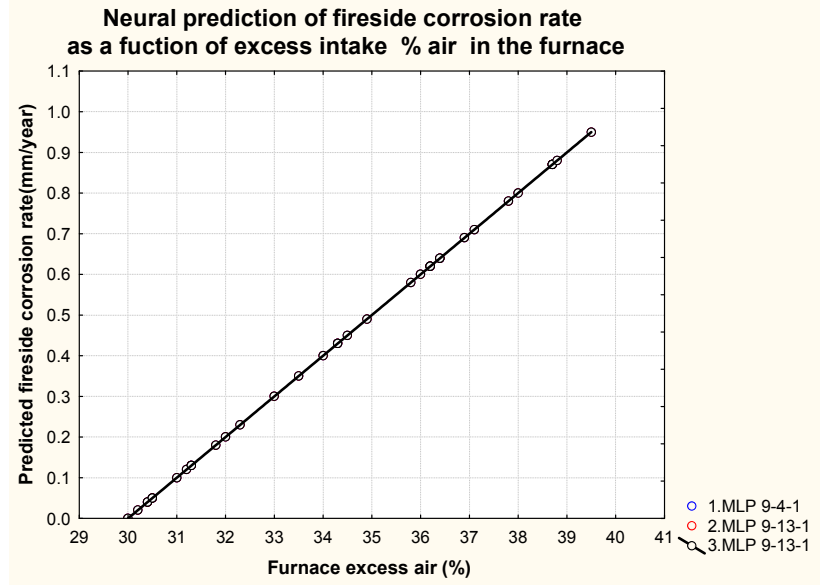

Figure 8. Prediction of fireside corrosion rate with excess intake air.

Fig. 8 depicts variation of predicted corrosion rate with the excess air in the furnace. It may be observed from the figure that the corrosion rate increases monotonically with an increased value of excess intake air percentage in the furnace. The sulfur in coal reacts with oxygen in the combustion air forming $\mathrm{SO}_{2}$, and, if the residence time and $\mathrm{O}_{2}$ content are more than sufficient, it forms also $\mathrm{SO}_{3}$. The initial sulfidation reaction seldom continues so as to result in internal sulfidation of the metal.

Fig. 9 and Fig. 10 depict-variation of the predicted corrosion rate with the wt $\%$ of $\mathrm{Na}_{2} \mathrm{O}$ and $\mathrm{K}_{2} \mathrm{O}$ in fly ash. It may be observed from the figure that the corrosion rate enhances with increased $w t \%$ of $\mathrm{Na}_{2} \mathrm{O}$ and $\mathrm{K}_{2} \mathrm{O}$ in fly ash. The corrosion rate varies from 0.01 to $0.94 \mathrm{~mm} /$ year (approx.) with respect to 0.3-0.4 and 1.0-1.5 wt $\%$ of $\mathrm{Na}_{2} \mathrm{O}$ and $\mathrm{K}_{2} \mathrm{O}$ in fly ash, respectively. The severe fireside corrosion of tube materials is caused by condensation/accumulation of low melting-point salts from the flue gas onto the tube surface since salts containing chlorides and sulphates of sodium and potassium, easily liquefying at the operating metal temperatures $[16,32]$. Reaction of alkali sulphates $\left(\mathrm{Na}_{2} \mathrm{SO}_{4}, \mathrm{~K}_{2} \mathrm{SO}_{4}\right)$ with Feoxides (deriving from oxide scales or ashes) in the presence of $\mathrm{SO}_{3}$ will result in 
the formation of alkali-iron trisulphates $(\mathrm{Na}, \mathrm{K})_{3} \mathrm{Fe}\left(\mathrm{SO}_{4}\right)_{3}$, held responsible for the degradation of coal-fired plant superheater tubes[15].

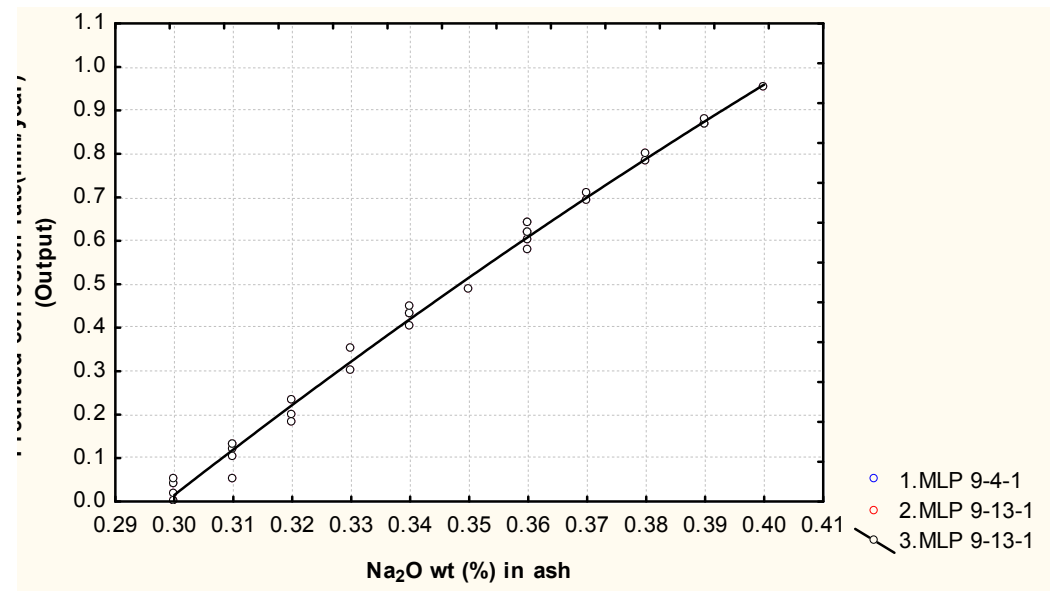

Figure 9. Prediction of fireside corrosion rate with $\mathrm{Na}_{2} \mathrm{O}$ content in ash.

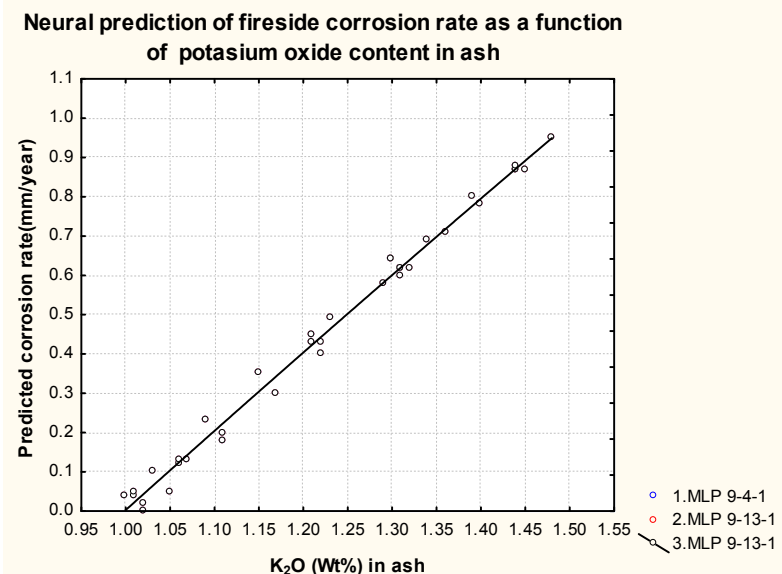

Figure 10. Prediction of fireside corrosion rate with $\mathrm{K}_{2} \mathrm{O}$ content in ash.

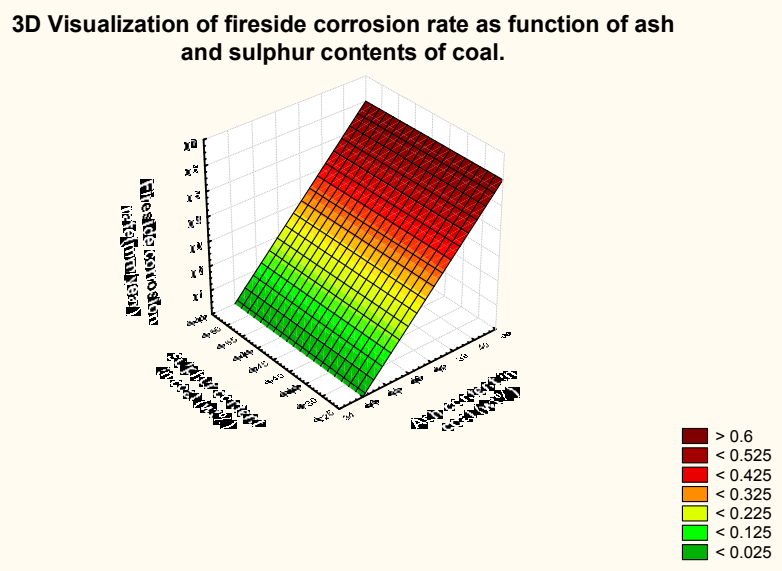

Figure 11. Variation of corrosion rates with coal ash and sulphur contents.

Fig. 11 shows a 3-D visualization of variation on predicted fireside corrosion rates as a function of coal ash and sulphur concentrations. It may be observed that the corrosion rate surface in 3-D framework depicting the variation of coal 
ash and sulphur content has a peak value which corresponds to a higher level of ash and sulphur content of coal.

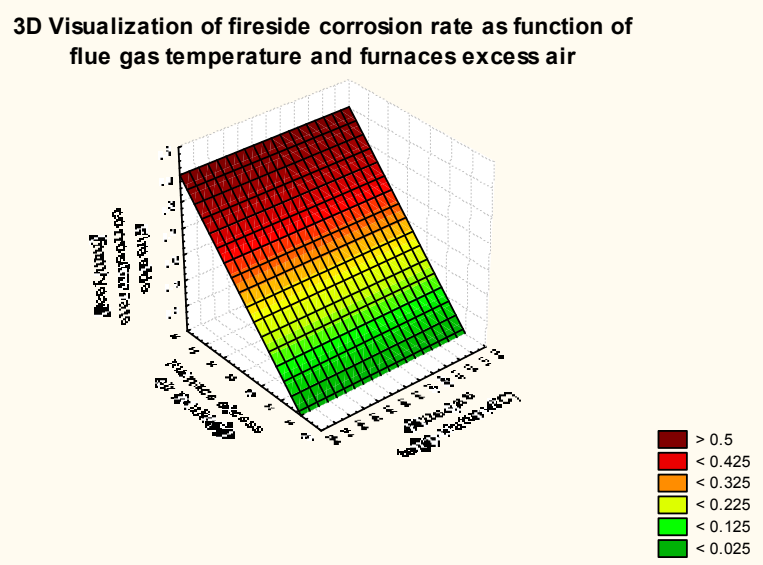

Figure 12. Variation of corrosion rates with excess air intake and flue gas temperature.

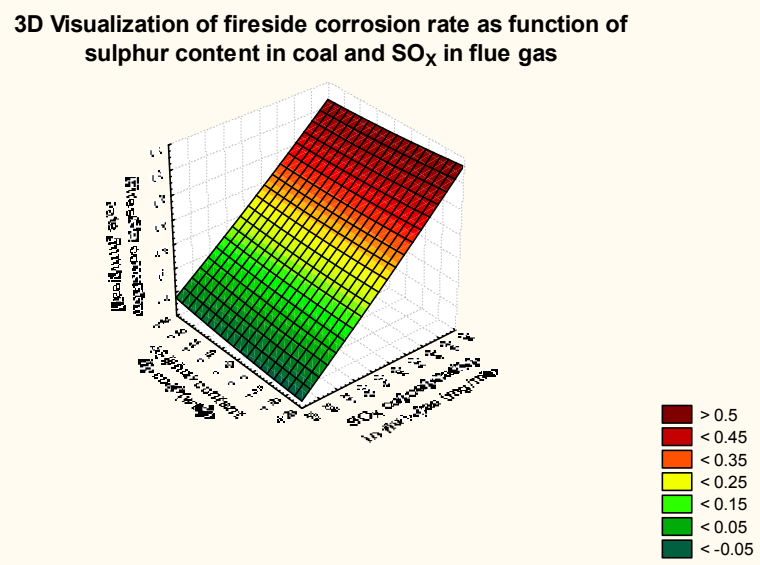

Figure 13. Variation of corrosion rates with coal sulphur content and $\mathrm{SO}_{\mathrm{X}}$ concentration in flue gas.

Fig. 12 shows 3-D visualization of the fireside corrosion rate as a function of operational parameters, namely, excess air intake and flue gas temperature. It may be observed that the corrosion rate surface in 3-D framework depicting the variation of excess air and flue gas temperature has a peak value corresponding to a very high level of excess air and elevated flue gas temperature. Fig. 13 shows 3-D visualization of the fireside corrosion rate as a function of coal sulphur concentrations and $\mathrm{SO}_{\mathrm{X}}$ concentrations in flue gas. It may be observed that the corrosion rate surface in 3-D framework depicting the variation of corrosion rate with coal sulphur content and $\mathrm{SO}_{\mathrm{X}}$ concentrations in flue gas has a peak value corresponding to high level of coal sulphur content and $\mathrm{SO}_{\mathrm{X}}$ concentrations in flue gas. Fig. 14 depicts the training and testing error generation as a function of training cycles during computation. It may be observed from this figure that the absolute error drops sharply from 0.06 to 0.01 at the very early stage of training (few cycles) and, subsequently, the training and 
testing errors asymptotically reduces to almost zero, with further increase in the number of cycles. It may be further noted that the error bounds in the measured data and neural computation are quiet small. Although several simulation results have been generated, however, only limited results are discussed in this paper.



Figure 14. Training and testing error convergence as a function of training cycles.

\section{Conclusions}

The proposed neural network model provides a reasonably accurate predictive framework and compares extremely well with the plant and experimental data. The ANN methodology shows good potential for predictions of the fireside corrosion rate as a function of input variables, namely, coal ash and sulfur contents, wt $\%$ of $\mathrm{Na}_{2} \mathrm{O}$ and $\mathrm{K}_{2} \mathrm{O}$ in fly ash and operating variables such as flue gas temperature and percentage excess air intake during combustion. This model has a relative advantage over other phenomenological and semi empirical models treating polluted data or data with complex functional dependence. Effects of coal composition and fly ash constituents and process parameters on the fireside corrosion rate have been investigated, and appropriately validated with the measured data. In the numerical domain, it has been found that the efficient gradient based network training algorithm does not require computation of numerically cumbersome Hessian matrix, or calculation of any matrix inverses. This algorithm potentially reduces the number of functions, facilitating faster convergence of training errors within a few cycles, with respect to fireside corrosion rate prediction.

\section{References}

1. Tomeczek J. Corros Sci. 2007;49:1862-1868.

2. Raask E. Mineral impurities in coal combustion. Washigton DC: Hemisphere Publishing Corp; 1985.

3. Dooley RB. The control of high temperature fireside corrosion. 2nd Edition. London: Central Electricity Generating Board; 1977.

4. Mayer P, Manolescu AV. Corrosion. 1980;36:369-373.

5. Ivanova IP, Svistunova LA. Teploenerge-tika.1971;18:60-63. 
6. Ivanova IP, Kaminskii VP, Belyaeva AG. Teploenerge-tika. 1972;19:16-18.

7. Ivanova IP, Marshak YuL. Teploenerge-tika. 1975;22:15-18.

8. Albrecht RF, Reeves CR, Steele NC. Artificial neural nets and genetic algorithms. Vienna: Springer-Verlag; 1993.

9. Burnod Y. An adaptive neural network: the cerebral cortex. London: Prentice-Hall; 1990.

10. Baum E. Neural Comput. 2004;2:248-260.

11. Simms NJ. Environmental degradation of boiler components. In: Oakey JE, editor. Power plant life management and performance improvement. 1 st ed. London; 2011.

12. Paul LD, Seelay RR. Corrosion. 1991;2:152-158.

13. Lee FCC, Lockwood FC. Prog Energy Comb Sci. 1998;25:117-123.

14. Yang QF, Ding J, Shen ZQ. Chem Eng Sci. 2000;55:797-804.

15. Thompson ML, Kramer MA. AIChE J. 1994;40:1328-1336.

16. Afgan NH, Carvalho MG, Coelho P. Appl Therm Eng. 1996;16:835-842.

17. Majidian A, Saidi MH. Int J Fatigue. 2007;29:489-495.

18. Dai MH. Int J Press Vessel Pip. 1995;63:111-117.

19. Afgan NH, Carvalho MG, Coelho P. Appl Therm Eng. 1996;16:835-844.

20. Majidian A, Saidi MH. Int J Fatigue. 2007;29:489-496.

21. Dai MH. Int J Press Vessel Pip. 1995;63:111-118.

22. Yagawa G. Int J Press Vessel Pip. 1995;63:303-311.

23. Trana C, Abrahamb A, Jaina L. Neurocomputing. 2004;6:185-195.

24. Nash SG, Nocedal J. SIAM J Optimization. 1991;1:358-365.

25. Xiang YY. IMA J Numer Analysis. 1991;11:325-334.

26. Boggs P, Tolle J. Acta Numerica. 1995;4:11-20.

27. Gould N, Toint P. System modeling and optimization, methods, theory and applications. Powell M, Scholtes S, editors. Netherlands: Kluwer; 2000.

28. Das SK. Ironmaking Steelmaking. 2013;40:298-305.

29. Ghosh I, Das SK, Chakraborty N. Neural Comput Applic. 2014;25:653660.

30. Tomeczek J, Palugniok H, Ochman J. Fuel. 2004;83:213-221.

31. Weulersse-Mouturat, Moulin K, Billard G, et al. Mater Sci Forum. 2004;461:973-980.

32. Otsuka N. Corros Sci. 2002;44:265-283. 